\title{
Retrieval of Selected Serial Citations: An Analysis through User Interviews
}

\author{
Rita H. Smith, Sook-Hyun Kim, \\ Theresa Pepin, and Steve Thomas
}

Members of the Working Group on Serials Holdings at a medium-sized university library sought to identify successful and unsuccessful search patterns for know-item serial literature. A user survey was modeled after Hanson and Serebnick's research on the public service functions of serial file systems. Results indicate that, in almost all cases, multiple factors contribute to an unsuccessful outcome. Information gathered through in-depth interviews of study participants will aid in the implementation of public access to serials holdings online and in the further evaluation and development of bibliographic instruction.

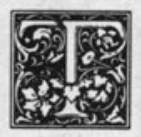

he University of Tennessee, Knoxville (UTK) Library maintains a printed Serials Holdings List, published in book format, as the major public bibliographic access point to serial publications in the library. By using the Serials Holdings List (SHL), clientele can obtain the call number, holdings, format, and branch location for serial items in the collection. They are required to search separate locations within the facility for bound volumes, microfilm, and current issues. The process has been fraught with problems both in interpreting the SHL and understanding the arrangement of the collection.

In 1987 the library reached a critical juncture regarding options for providing serials holdings information to library users. The pending move into a new central library facility, merging collections from the main and undergraduate libraries while continuing to maintain three branch libraries, would necessitate numerous changes in the holdings and location in the SHL. A hard copy would not be ready in time for fall quarter which started immediately following the move. In the new facility the card catalog was to have a less prominent location and the online catalog would become the access point for library holdings. However, call numbers and holdings for serials were not yet accessible to the public through the online system, and all indications were that this feature was not going to be ready soon.

In addition, the annual book form of the SHL had become quite costly to produce. It had grown to 35,000 records, and in recent years the serials department staff had input an average of 3,000 changes and 1,000 new entries yearly, to produce the list at a cost of $\$ 15,000-\$ 20,000$. The SHL is also published quarterly in microfiche format at a rather low cost and distributed to other libraries in the region. However, onsite, the microfiche format is extremely unpopular with public service staff, student and faculty library users and constitutes a public relations dilemma. Given

Rita H. Smith is Associate Professor and Reference Librarian; Sook-Hyun Kim is Associate Professor and Head Serials Cataloger; Theresa Pepin is Assistant Professor, Graduate School of Library and Information Science, and Manager, Computer Science Laboratories; and Steve Thomas is Assistant Professor and OLIS Coordinator for Technical Services, University of Tennessee, Knoxville, Tennessee. 
the choice of using the hard copy or the microfiche copy, users and staff alike opt for the book format on first try, even when it is out-of-date.

The working group on serials holdings was appointed to consider options for public access to information about the serials collection. Prior to moving into the new building seemed a particularly appropriate time to evaluate the utility of the serials files and the accessibility of the serials collection. As part of our deliberations, we sought to outline how a student used the serials collection. More specifically, having a citation to a known-item serial publication in hand, how they accessed and retrieved the desired material.

\section{LITERATURE REVIEW}

One of the articles the committee discovered in reviewing the literature on public access to serials, was a user study conducted at the Indiana University geology library by Elizabeth Hanson and Judith Serebnick that identified successful and unsuccessful patterns of searching serials, on the part of students who had not used the library previously. ${ }^{1}$ The study employed citations, questionnaires, interviews, and critical analysis of 130 factors related to selected variables to determine the efficiency and effectiveness of the serial file system. The committee decided to replicate this survey. Hanson and Serebnick present a methodology for "describing, analyzing and evaluating the public service functions of serial file systems, with emphasis on evaluation. ${ }^{\prime 2}$ They supplied us with copies of their evaluation matrices and survey instruments.

To update the bibliography provided by Hanson and Serebnick we ran computer searches in ERIC, LISA, and SOCIAL SCI$S E A R C H$. Little new was located. A review article by John Mansbridge contributed an excellent bibliography of availability/accessibility studies which identifies research on both monographs and serials accessibility, as well as discussing the most useful methodologies employed in past studies. ${ }^{3}$ In recent years there have been relatively few studies identifying the problems associated with serials access and retrieval. ${ }^{4}$ The research varies widely and few common themes, other than those confirming that it is a difficult process, seem evident. Gary Golden, Susan Golden, and Rebecca Lenzini suggest that the small number of usage studies could be due to the wide variance in the handling of serials files. ${ }^{5}$

In addition to the Hanson and Serebnick study, the most useful research on serials access from our point of view, came from Marjorie Murfin's frequently cited study on periodical accessibility and from unpublished reports on periodical access done in-house previously by Rita Smith. ${ }^{6,7}$ The studies by Murfin and Smith attempted to find out how often library users failed to find periodical titles to which the library subscribed and the reasons for this failure. They were particularly interested in what percentage of the failure could be attributed to library problems as opposed to user error. While Murfin, Smith, and Hanson and Serebnick reported success rates that varied widely (from $43 \%$ to $69 \%$ ), evidence from all three studies indicated similar problems were encountered by study participants. Factors that led to failures generally fell into three categories.

By far the greatest difficulty came in finding periodicals that were shelved in various locations throughout the building as a result of format. Separation of bound, microfilmed, and current periodicals was a major factor contributing to high failure rates. Not only were many study participants unfamiliar with the arrangement of the collection, but they did not understand they could use the serials list or directory to find this information. Success in finding periodicals was affected by whether the study participant consulted the library's serials listing, what they did with the information they received from the lists, and mistakes they made using the lists.

The second major failure category was unexplained user error. Even though they were looking in generally the correct area of the library, study participants did not find periodicals that were available at the time of their search. Carelessness and lack of experience using the library may have been contributing factors, in this case. 
Hanson and Serebnick reported that higher class rank, more frequent use of the library, and more intensive bibliographic instruction was related to higher success rates.

The third biggest problem area for study participants was their inability to recognize that they may have made errors and that they should ask for assistance. If students did not find the material in the serials list or on the shelf they generally reported that it was not available in the library. Hanson and Serebnick further noted that many unsuccessful searchers did not know how to ask for information in a clear and precise manner. As a result, when they did ask for help, they were often not given the best possible assistance.

Betty Bengtson conducted a survey of the effectiveness of the Serials Holdings List of the UTK Library in 1986 through a mail questionnaire sent to off-campus users, a random sample of in-library users, and interviews of selected library staff members. ${ }^{8}$ Her surveys showed that the Serials Holdings List is an effective tool and that $84 \%$ of the in-library users were successful at finding what they wanted. It is noteworthy that approximately $80 \%$ of those who were successful reported having received instruction in how to use the List. For almost half of those who were unsuccessful, there appeared to be no explanation, as there were no apparent complicating factors. The remaining unsuccessful searches could have been a result of confusing filing rules, the use of crossreferences, and the difficulty of locating corporate authors and conference proceedings. Problems most cited by all those surveyed had to do with legibility, confusion about certain data elements, filing order, and lack of additional access points.

\section{METHODOLOGY}

In choosing to pattern our research after the Hanson/Serebnick study we noted that their intent was "to suggest a useful approach toward the evaluation of current systems, either to improve efficiency or to redesign them in anticipation of an online serials control system. ${ }^{\prime \prime}$ With this in mind our group decided to employ, in part, the methodology designed by these research- ers. That is, we sought to identify successful and unsuccessful search patterns of a group of 15 students for known-item serial literature in the Hoskins (Main) Library.

This technique made use of citation retrieval, in-depth interview, and critical analysis of factors entailing success or failure on the part of either the system or the searcher. We were intent on determining how retrieval rates could be improved by better access and/or better instruction. UItimately the committee felt that the library system would find the information beneficial in the further development and implementation of public access to serials holdings online. As with the parent study we kept our sample group small to allow for more in-depth interviews and subsequent analysis.

The initial step was to compile 15 packets incorporating 5 citations each for a total of 75 citations reflecting articles in bound volumes, current unbound issues, issues being claimed, in binding, or in microforms. Approximately 300 citations were drawn from online searches as a stratified random sample of Science Citation Index, Social Science Citation Index, and Arts and Humanities Citation Index. The 75 citations were selected from the pool of 300 citations such that all prospective library system conditions could be represented (binding, in claim process, microformat, circulating). These were ranked roughly by level of difficulty from easy to hard and more or less evenly distributed by those levels among the 15 participants.

A librarian located the citation and recorded the "trail" to the location for each citation exactly, so that a student assistant would later be able to verify the item's availability immediately before the student subject began their search. This trail (call number, location or status of the item) was recorded on a master copy of the citation and later compared to the subject's worksheet to determine whether the search was successful or not.

Fifteen student participants were hired through newspaper ads and signs displayed on campus. An even distribution of class standing from freshman to graduate students was sought, but there were no other qualifications. As it turned out, 
the sample included 3 from each class standing with a variety of college majors represented. Their experience level in using the main library also varied from never to daily.

Research team members met each participant by appointment in the library and described the study. Each study participant was given 5 references to serial publications and allowed 1 hour to complete the searches and annotate a worksheet for each search (appendix A). Afterwards, each was asked to complete a questionnaire (appendix B) and submit to a structured interview whereby the interviewer sought to clarify or amplify notes on the search worksheets and answers on the questionnaire. Subjects were paid $\$ 10$ each for approximately two hours of their time.

Searches were checked against the master trail and judged to be either successful or unsuccessful. A successful search was defined as one in which the student either retrieved the appropriate volume or issue or determined that the volume or issue was at the bindery, being claimed, in circulation, or not held by the library. The search pattern for each was reconstructed from answers and notes on the worksheet and the interview questionnaire.

Responses to the questionnaire and the interview were examined to establish the variables-such as access tools, staff assistance, physical locations-and the success/failure factors to be considered for each variable. The factors and variables were categorized to the extent possible on spreadsheets, thereby forming the basis for our reported results.

\section{RESULTS OF CITATION SEARCHES}

Of the 75 citations, the search for 47 (64\%) was considered successful; for 28 $(36 \%)$ the search was not successful. This figure falls near the high side of the range of $43 \%$ to $69 \%$ reported in previously cited periodical accessibility studies. ${ }^{10}$ Similar to the Bengtson study, where participants claimed to have found 11 titles (or $5 \%$ ) that could not have been retrieved from our collection, we also had a small percentage (5\%) of false reports. ${ }^{11}$
Spreadsheets provided a detailed analysis of the factors that contributed to successful and unsuccessful searches. The factors were broadly grouped as system problems vs. patron problems. Within each of these categories, more specific reasons were assigned, such as tools, location dispersal, and staff assistance. Patron problems included carelessness, a reluctance to request assistance, imprecise questioning, false assumptions made, a lack of pursuit, a report of false information, and running out of time. There were also unexplained errors. In almost all cases, multiple factors contributed to an unsuccessful outcome, so it is difficult to state with confidence that a certain percentage occurred as a result of system failures or that another percentage was a result of patron errors.

\section{Patterns Evident \\ in Both Successful \\ and Unsuccessful Searches}

The Serials Holdings List was the preferred tool in both successful and unsuccessful searches. All 47 successful searches involved the $S H L$, as did 23 of the 28 unsuccessful ones. Of the 47 successful searches, 43 located the correct entry in the SHL and obtained the correct call number. The other 4 successful searches were the result of not finding an entry in the SHL and making the correct assumption that the library did not subscribe to the journals in question. Of the 23 unsuccessful searches in which the SHL was used, the correct entry was identified in only 15 . (Reasons why the other 8 failed will be considered below.)

Neither the card catalog nor the online catalog was widely used in successful or unsuccessful searches. Three of the 47 successful searches included the card cata$\log$, although it was an unproductive step in 2 cases. None of the successful searches listed the online catalog as a consulted source. ${ }^{12}$

Six of the unsuccessful searches included the card catalog. For each this was a fruitless step. For 5 of the 6 , no entry was found; for the sixth, an incorrect call number was obtained. For 3 of these 6 , the card catalog was the only tool used to try to lo- 
cate the item. Two of the other searches showed use of the online catalog to obtain the correct call number. In the sixth case (where a wrong call number was obtained from the card catalog) the SHL was also consulted and an incorrect call number was again recorded.

\section{Patterns Evident \\ in Successful Searches}

Three-fourths of the searches (a total of 35 ) yielded the desired item. Of these, 23 were found in the stacks, 9 in current periodicals, and 3 in microforms. Table 1 summarizes successful search results.

Of the searches where the item was found, 20 (over $57 \%$ ) were found in the first location checked. However, it is unknown in some cases whether this was a matter of choice or luck. With the 3 items in microforms, this correct location was noted from the SHL in 2 cases and from the card catalog in the third. For the others, the reason why the stacks or current periodicals was the correct first choice is unclear (as much to the students as anyone else).

The other 15 searches (nearly $43 \%$ ) where the item was found required a second location to be checked. That is, the searcher was required to realize that jour-

\section{TABLE 1}

\section{SUMMARY OF SUCCESSFUL} SEARCH RESULTS

\begin{tabular}{lr}
\hline \hline & No. \\
\hline Citations Found & \\
In stacks & 23 \\
In current periodicals & 9 \\
In microforms & 3 \\
$\quad$ Total & 35 \\
Citations Not Foundt & \\
Not found in SHL, assumed (correctly) & \\
$\quad$ that library did not subscribe & 4 \\
Found in SHL, determined location other & \\
$\quad$ than main & 5 \\
Found in SHL, determined needed vol- & \\
$\quad$ ume not held & 1 \\
Found in SHL, determined needed vol- & \\
$\quad$ ume in binding & 2 \\
$\quad$ Total & 12 \\
\hline
\end{tabular}

"Twenty found in first location checked, fifteen found in second location checked.

tThese searches were judged successful because disposition of the material was correctly determined. nals of various ages might be in either current periodicals or in the stacks and that it was necessary to check the alternate location for current or back issues.

One-quarter of the searches (12 in all) were labeled "successful" even though the desired item was not found. (See table $1)$. In these cases, the study participant successfully determined the status of the material, that is, not held in binding or in a branch library. Success was the result of a combination of observations by the searchers and information supplied by library staff when assistance was sought.

\section{Patterns Evident in Unsuccessful Searches}

There were often several factors that combined to produce an unsuccessful search and our attempts to outline these come close to defying categorization. Discussed below are what are judged to be the initial or principal reasons for failure. Table 2 summarizes unsuccessful search results.

We have already mentioned that in 5 searches the SHL was not used. These searches were all conducted by the same user. He reported using the card catalog, but he failed to find any entries there. He did report finding call numbers for the 2 items he searched in the online catalog, although he seemed unclear how to proceed, and did not seek assistance at any point in his searching.

In the other 23 unsuccessful searches, the SHL was used, but the correct call number for the item was not obtained onethird of the time. The reasons for these failures are not completely clear. One title, for which the searcher reported finding no entry, was entered as an acronym and thus was not at the expected point in the alphabetical listing. One searcher reported finding the entry in question, but did not note the call number. Another listed only a partial call number. Five other searches seemed to go astray with the selection of an incorrect entry.

In the other 14 unsuccessful searches, the SHL was used correctly to determine the call number of the desired item. Four of these could have been successful searches if other information in the SHL 
TABLE 2

SUMMARY OF UNSUCCESSFUL SEARCH RESULTS

\section{Tool Related}

Not found in card catalog, did not pursue

Call number found in OPAC, volumes not found, did not pursue (one in stacks, the other not yet received)

Not found in serials holdings list (listed under acronym)

Wrong entry in SHL selected, yielding incorrect call number

Reported found in SHL, but no call number or partial call number recorded Total

No.

Location Related

Noted location was other than main, but did not note that subscription had stopped

Did not note locations were music and microforms

Checked only current periodicals ( 2 items in stacks, 1 being claimed)

Checked only stacks ( 1 item in current periodicals, 1 in storage, 1 not held)

Checked current periodicals and stacks ( 1 item in current periodicals, 1 in stacks [user went to wrong floor], 1 not held [subscription stopped]

Claimed found:

in microforms (both really in stacks)

in current periodicals (actually in bind-

ing)

in stacks (actually in binding)

Total

Note: There were, of course, often several problems with a particular search. Counted here is what is judged to have been the initial problem.

such as format available, branch library location, and holdings had been noted.

In the remaining 10 searches, the problems were with the manner in which the correct information from the $S H L$ was used. In all cases it was a matter of looking in the wrong place or reporting incorrect locations on the worksheets.

\section{Summary}

An analysis of the information collected through the worksheets, the questionnaires, and the interviews, indicates that the differences in results between successful and unsuccessful searches may be attributed to the degree that the student could: (1) identify the correct entry in the $S H L ;(2)$ translate the holdings informa- tion to determine if the desired item is held; (3) identify the correct location for the item; and (4) determine if the item is "current" or "bound" (or is willing to check both).

\section{GENERAL OBSERVATIONS}

Much of the evaluation in Hanson/ Serebnick focuses on the behavior of the individual as compared with other individuals in the group of 15 study participants. In contrast, we have found it more fruitful to concentrate our analysis on the evidence of each individual's work with the 75 citations. This has been true for a number of reasons, chief among them the fact that it is impossible to capture all library system conditions in 5 citations and so it is difficult, we believe, to rigorously compare the individual performances of the participants. Despite our efforts to arrive at an equitable mix of citations for each participant, a comparison of performance is bedeviled by several other variables, few of which can be held constant.

While acknowledging the caveat about comparing among and generalizing from this small number of participants, we will make some observations about the study participants from our data. Basic facts about performance of the participants are: only 1 person found all 5 citations in their packet; there was also only 1 person who found none of the 5 citations given him; 5 students found 4 of $5 ; 5$ students found 3 of $5 ; 3$ students found 2 of 5 .

\section{".. . grade level and library experi- ence did not seem to have much to do with the degree of success."}

It is interesting that grade level and library experience did not seem to have much to do with the degree of success. This is contrary to the results of the Hanson/Serebnick study. ${ }^{13}$ The perfect score was made by a junior in marketing and the zero score was made by a graduate student in engineering. In fact, none of the graduate students scored above 3 out of 5 , even though their confidence levels were 
very high. The freshman and sophomore students were less confident and seemed less sure of where to start looking, but as a group did as well as the upperclassmen. The less experienced users also expressed doubts about their abilities, but many times did as well or better than their more experienced counterparts. Perhaps this was because they asked for help more often and/or were more careful in their work.

The display of self-confidence is also different with respect to specific variables; that is, students seemed to be more confident in their use of bibliographic tools (only 5 searches showed evidence of a request for assistance with the entry) than in their physical-location search for the actual item (where 13 searchers did request assistance at service desks). In fact, requests for assistance with location in many cases should also have entailed assistance with the bibliographic entry.

The final report from the working group on serials holdings outlined the steps that librarians perceive to be necessary to verify a title in our serials files (appendix C). In fact, and not surprisingly, our study demonstrated that the search patterns of most students is much abbreviated: (1) in searches to locate journal titles, students used the Serials Holdings List; (2) they used it to obtain call numbers only; and (3) they did not check alternate bibliographic tools if they did not find the title in the Serials Holdings List.

In the UTK Library, it is obvious that the book form of the Serials Holdings List is a well-known source. From freshmen to graduates, all but one of our students used this tool. There was infrequent use of the card catalog, even less use of the online catalog, and no use of the microfiche Serials Holdings List. Directly related to awareness of the Serials Holdings List was the fact that 13 of 15 study participants had received some sort of library instruction. The one person who did not use the List for any searches, and who scored a zero in the survey, had not received any library orientation or instruction. (This person is an international student doing graduate work at UTK and he demonstrated to us a need for some special attention to this group.) Still, library instruction appears to be reaching a large audience because our subjects were a mix of class standing and majors. Without a doubt, we had been successful at instilling the knowledge that the Serials Holdings List was the access tool for serial publications.

In fact it appeared that we had informed people about the Serials Holdings List as the source for finding serials, to the exclusion of almost every other means. Thus, widespread public relations and library orientation will be necessary to teach new means of access to serials holdings as these become available. When asked, the majority of the study participants indicated that they would not be adverse to using the online catalog to locate information on serials; indeed, they welcomed the prospect of one source in which to search for all materials.

In our interviews, the circumstance students complained about most often was dispersion of various formats throughout the building. This observation again confirms the results of both the Murfin ${ }^{14}$ and the Hanson and Serebnick ${ }^{15}$ studies. Study participants did not know whether to check the current periodicals room, microforms, or stacks for citations from recent years. Most ended up checking more than one location and expressed frustration in trying to figure out where to go on a consistent basis. Some wondered why there was no way to look up where a particular issue would be shelved.

\section{FURTHER RESEARCH}

Our work on this project has demon. strated the difficulty of analyzing and attributing the reasons for success and failure-particularly for failure-in searches for the serial literature. There are several points that deserve further examination in any future studies of this type.

1. Given a random stratified sample, such as that used in this study, how worthwhile is it to take the sample and divide it among participants such that the performance of participants, one with another, might be compared? What this requires is an attempt to rate each citation in terms of its level of difficulty and then distribute those equitably among the partici- 
pants. Hanson and Serebnick did rank the level of difficulty of their citations, but then did not correlate those results. ${ }^{16}$

2. Given a random stratified sample, how possible is it to arrive at an adequate number of examples of the many availability and accessibility conditions that prevail in the typical research library?

3. Given that at least a small percentage of participants can be expected to claim to find items when they have not, might it be better to require some proof that the citation was, in fact, retrieved? Perhaps a copy of the first page of the article?

4. Given that the citations sample will include items not held, at what point in the search do we decide that a searcher has been "successful" in not locating the item, because he has correctly determined that the item is indeed not held?

Another area that we believe would be a fruitful one for continuing research would be to examine the differences that could be anticipated between the form in which titles are typically cited in the literature and the form of entry by which they are listed in library access tools.

\section{PRACTICAL IMPLICATIONS}

Results from the study indicated to our committee the importance of considering the problem of the physical distribution of the serials collections among several locations. For example: we will need to de- velop effective means for indicating the location of a particular issue in the online catalog; we may need to provide pointers to alternate locations of current and back issues.

Because the Serials Holdings List has become an essential tool for locating serials in the libraries, we must plan for promotion and instruction for any tool that replaces or supplements it, especially the online catalog.

Finally, an important added benefit of our study turned out to be simply the opportunity to observe and interact with student users of the UTK Library. Interviews with the study participants were a valuable part of the data derived from this project. The process of analyzing the steps that students went through to search for serials reinforced for us just how complex a process this can be. As a group, the participants appeared interested in being part of a research project and were willing to discuss their searches and the library, in detail, during the follow-up interviews. This study points to the value of occasionally meeting with our clientele for their input. The working group on serials holdings has suggested to the UTK Library administration that student interviews be used in future efforts to evaluate implementation of a new printed holdings list and/or serials holdings displays in the online catalog.

\section{REFERENCES AND NOTES}

1. Elizabeth Hanson and Judith Serebnick, "Evaluation of the Public Service Functions of Serial File Systems," College and Research Libraries 47:575-86 (Nov. 1986).

2. Ibid, p.575.

3. John Mansbridge, "Availability Studies in Libraries," Library and Information Science Research 8:299-314 (1986).

4. The following are typical serials access studies: Paul T. Adalian, Jr., Ilene F. Rockman, and Ernest Rodie, "Student Success in Using Microfiche to Find Periodicals," College and Research Libraries, 46:49-54 (Jan. 1985); Gary A. Golden, Susan U. Golden, and Rebecca T. Lenzini, "Patron Approaches to Serials: A User Study," College and Research Libraries 43:22-30 (Jan. 1982); Barbara P. Pinzelik, "The Serials Maze: Providing Public Service for a Large Serials Collection," Journal of Academic Librarianship 8:89-94 (May 1982); William Watson, " A Periodical Access Survey in a University Library," College and Research Libraries 45:496-501 (Nov. 1984).

5. Golden, Golden, and Lenzini, "Patron Approaches," p.22.

6. Marjorie E. Murfin, "The Myth of Accessibility: Frustration \& Failure in Retrieving Periodicals," Journal of Academic Librarianship 6:16-19 (Mar. 1980).

7. Rita H. Smith, "Periodical Accessibility Study," University of Tennessee, Knoxville Library. Typescript (1980-81). 
8. Betty G. Bengtson, "The Serials Holdings List of the University of Tennessee Library: An Assessment and Recommendation, " University of Maryland, University College, Graduate School Management Project. Photocopy (1986).

9. Hanson and Serebnick, "Evaluation of the," p.575-76.

10. Hanson and Serebnick, "Evaluation of the," p.580; Murfin, "The Myth," p.17; Smith, "Periodical Accessibility (1980-81)."

11. Bengtson, "The Serials Holdings," p.17-18 (1986).

12. The lack of use of the online catalog was not unexpected, given the fact that call number and holdings data for serial records were not available. It should also be noted that at the time of the study public use of the online catalog had just begun, and though gaining in popularity, only a small number of online terminals were available for public use.

13. Hanson and Serebnick, "Evaluation of the," p.581.

14. Murfin, "The Myth," p.18-19.

15. Hanson and Serebnick, "Evaluation of the," p.585.

16. Ibid, p.579.

\section{APPENDIX A: EXAMPLE OF WORKSHEET}

JO-

Place a checkmark next to the results of your search.

I found this article.

Where?

Call Number:

I could not find the article.

Because:

The library doesn't subscribe to the journal.

The library subscribes to the journal, but the specific issue I need wasn't on the shelf. Do you know why it wasn't on the shelf?

Other. Please specify

How did you try to find the article?

\section{APPENDIX B: SURVEY QUESTIONNAIRE}

1. What is your association with the university? (Circle one.)

Freshman

1

Sophomore

2

Junior

3

Senior

4

Graduate Student 5

2. What is your major field of study?

3. How often do you use the UT library system to look for a particular book, periodical, etc.? (Circle the number that most closely applies.)

Less than once each quarter

Two or three times each quarter 2

Two or three times a month 3

About once a week

More than once a week

1
2
3
4
5

4. Have you had instruction from library staff and/or faculty in how to use the UT library system? Yes No. If yes, briefly indicate what the instruction included. 
Classroom instruction:

One-on-One instruction:

\section{THE REMAINING QUESTIONS RELATE TO YOUR USE OF THE LIBRARY TODAY}

5. If you did not find one or more items, what do you consider to be the major reasons for this? What were the major problems you had in your search?

6. How helpful were the following sources in your searches?

Online Catalog

\begin{tabular}{|c|c|c|c|}
\hline Very & Somewhat & Not & Did not \\
\hline Helpful & Helpful & Helpful & Consult \\
\hline
\end{tabular}

Card Catalog

Shelf List

Serials Holdings

List (Orange Book)

Serials Holdings

List (microfiche)

Library Staff

If you had trouble using any of the above, what were the problems?

Which of the above sources would you prefer to use when looking up the call number and location of a periodical?

7. Where do you typically look first for periodicals? How do you get started?

8. What are some of the features of the library that help you, or make it easier for you, to find materials?

9. What would you suggest the librarians do to make the library easier to use?

10. As you look back on your search, what do you think is the best method, or search strategy, for locating materials in this library?

\section{APPENDIX C: STEPS TO LOCATE PERIODICALS IN THE UTK LIBRARY}

1. Obtain citation
a) serial title
b) volume
c) issue
d) pages
e) date

2. Determine availability
a) check
1) serials holdings list
2) online catalog
3) card catalog
4) holdings lists of area libraries or ILS if not at UTK

b) note
1) location
2) format
3) call number

3. Interpret availability information
a) Do we own desired volume?
b) Is it "current" or "bound" volume?
c) Ask for help with interpretations of abbreviations, symbols, or information that is unclear.

4. Check shelves by call number
a) current issues in periodicals
b) bound volumes in stacks
c) microformats in microforms

5. If not found
a) ask at
1) periodicals desk 
3) microforms desk

4) reference desk

5) reserve desk

b) to determine if

1) at bindery

2) in circulation

3) in use in building

4) ready to reshelve

5) not yet received

6. If unavailable at UTK Library
a) order through ILS
b) request through serials
c) go to another library
d) give up search 